Research Article

\title{
Use of garenoxacin: a new generation antibiotic for surgical infections
}

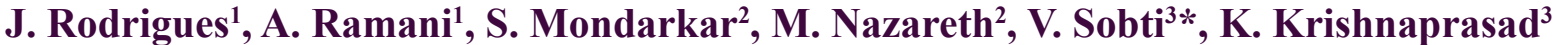

${ }^{1}$ Department of General Surgery, Goa Medical College, Goa, ${ }^{2}$ Resident Medical Officer, Goa Medical College, Goa, ${ }^{3}$ Medical Services, Glenmark Pharmaceuticals, Mumbai, Maharashtra, India

Received: 18 December 2014 Accepted: 09 January 2015

*Correspondence to:

Dr. Vikram Sobti, Email: vikramsobti@yahoo. com

Copyright: (C) the author(s), publisher and licensee Medip Academy. This is an openaccess article distributed under the terms of the Creative Commons Attribution NonCommercial License, which permits unrestricted noncommercial use, distribution, and reproduction in any medium, provided the original work is properly cited.

\begin{abstract}
Background: The management of skin and skin structure infections (SSSI) still continues to be global challenge. USFDA has given strong recommendation for adequate empirical antibiotic coverage to avoid further complication of the wounds. Wound complications, especially in the diabetic population, patients with low immunity remains a big challenge though other factors like site of the wound, age of the patients also play an important role.

Methods: A retrospective observational study was conducted to analyze clinical utility of garenoxacin for surgical prophylaxis. A total of 100 patients, 30 patients with diabetic foot and 70 patients with post-surgical intraabdominal wounds who were prescribed garenoxacin $2 \times 200 \mathrm{mg}$ as stat dose prophylactically. Swab culture from the wound slough and drain tube samples were sent for culture/sensitivity on day 0 , day 5 , and day 7 . Wound healing was evaluated by estimating slough discharge, size of the wound, vascularity, and overall healing. They were categorized as treatment failure group, when sough/drain-discharge reduction was $\leq 50 \%$, improved if sough/drain-discharge reduction was $50-75 \%$ and cure when sough/drain-discharge reduction was $75-100 \%$.

Results: The healthy granulation tissue was observed post 7 days therapy of garenoxacin $2 \times 200 \mathrm{mg}$ in diabetic foot ulcer (DFU) patients when administered empirically before surgical debridement. In patients with post-operative infectious intraabdominal wounds, the most common isolated organisms were Enterococcus, Acinetobacter and Klebsiella. Post garenoxacin therapy used as switch therapy empirically for 5 days resulted in $100 \%$ sterile culture. While evaluating slough/draindischarge in DFU patients, $84 \%$ patients showed cure and $16 \%$ showed improvement at the end of day 7 and in patients with post-operative infectious intra-abdominal wounds cure was observed in $86 \%$ patients showed cure and $14 \%$ patient showed improvement. No side effects were reported during the study.

Conclusions: Administration of garenoxacin used as empirical therapy for surgical prophylaxis and as switch therapy in patients with DFU s and post-surgical infectious wounds for the period of 5-7 days has been found effective indicating its wide spectrum of action.
\end{abstract}

Keywords: Garenoxacin, Fluoroquinolone, Skin and skin structure infections, Staphylococcus aureus

\section{INTRODUCTION}

A wound is an outcome of physical disruption of the skin, which is the screening barrier for the establishment of infections by the pathogens in the internal tissues. When bacteria invade this barrier, it results in infection. ${ }^{1,2}$ The most common underlying event for all wounds is trauma which may be accidental or elective. Wounds are prone to super-infection or are likely to develop complications in some certain populations like diabetics or in geriatric age group. Initially only the skin and superficial soft tissue may be involved, but as the infection progresses, it is likely to including fascia, muscle, joint and bone. Successfully treating these infections requires carefully assessing wound management protocols such as wound cleaning and debridement, dressing and selecting most appropriate empirical antibiotic therapy. ${ }^{3}$

Appropriately administered antibiotic prophylaxis which is recommended for all clean-contaminated, contaminated and dirty procedures reduces the incidence of surgical wound infection. ${ }^{4}$ Quinolones demonstrate excellent activity 
against the most common pathogens in skin infections, including Staphylococcus aureus. ${ }^{5}$ This study was conducted to evaluate the efficacy and safety of garenoxacin, a new generation fluoroquinolone in managing skin and skin structure infections (SSSI), when prescribed as an empirical therapy in infectious wounds.

Like other fluoroquinolones, garenoxacin acts on DNA gyrase and DNA topoisomerase IV to inhibit the transcription and replication of DNA. ${ }^{6}$ However, garenoxacin demonstrates unique structure-activity relationship to offer one of the lowest MICs against respiratory pathogens with low potential for resistance development. Garenoxacin demonstrates wide spectrum of antibacterial activity against Gram-positive, Gram-negative, atypical and anaerobic pathogens and also demonstrates low mutation prevention concentrations preventing the development of resistant strains with double-point mutations. Though it has a labeled indication of being prescribed respiratory tract infections, but with its pharmacodynamic and pharmacokinetic correlates promises to have the therapeutic efficacy while treating SSSIs, Urinary tract infections, intraabdominal infections and gastrointestinal infections including enteric fever. ${ }^{7}$

\section{METHODS}

This study was conducted to understand the efficacy and safety of fluoroquinolones in the treatment of postoperative wound infections (intraabdominal and diabetic foot) when being prescribed prophylactically as an empirical therapy. A total of 100 post-surgical patients with age $\geq 18$ years were included in the study. Inclusion criteria for diabetic foot ulcer (DFU) were the wounds with purulent or sero-purulent discharge with foul smell and patients with intraabdominal wounds who have undergone operative procedures like appendectomy, laparotomies were included in the study.

\section{Study design}

This was a retrospective observational study, which was conducted over the period of 6 months involving 250 cases of SSSIs. Of these, 30 patients with DFUs and 70 patients post-operative infectious intraabdominal wounds were further analyzed. In all of these cases garenoxacin was prescribed at the dosage of $2 \times 200 \mathrm{mg}$. for the period of 5-7 days. Swab cultures from the wound site for the culture and patients were evaluated for the wound status and improvement related to discharge from the wound site, vascularity overall healing.

Uses of non-steroidal anti-inflammatory drugs, antiinflammatory enzyme preparations were allowed as adjuvants during the treatment. Antipyretic and analgesics were permitted only on need basis. Other antibacterial agents and steroids were not permitted during the observation period. In diabetic population, oral hypoglycemic agents or insulin s/c were permitted to control the blood sugar levels with-in the normal range

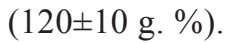

In patients with DFUs garenoxacin $2 \times 200 \mathrm{mg}$ was prescribed as a prophylactic antibiotic therapy 2 days before surgical debridement to avoid complication of wounds, routine dressings were changed slough removal, which was carried out in these patients daily. Garenoxacin continued for the total of 7 days in these patients. Swab culture was sent for all the patients on the day when debridement was done and on day 7 as summarized in Table 1.

In 70 patients with post-surgical intra-abdominal wounds, garenoxacin $2 \times 200 \mathrm{mg}$ was prescribed following parenteral antibiotic administration during surgery and drain sample collection schedule has been summarized in Table 2.

One day prior to surgery, the patients were placed on parental administration of three drugs viz., ciprofloxacin $200 \mathrm{mg}$ b.i.d. IV, ceftriaxone + sulbactam $1 \mathrm{~g}$ b.i.d., IV and metronidazole $400 \mathrm{mg}$ t.i.d. On the day surgery, when the drain was placed, immediately first sample of drain discharge was collected and sent for culture. After $24 \mathrm{hrs}$ of surgery when patient was allowed orally, ciprofloxacin $200 \mathrm{mg} \mathrm{I} / \mathrm{V}$ was replaced with garenoxacin $2 \times 200 \mathrm{mg}$. $\mathrm{P} / \mathrm{O}$. Second sample of drain was collected on day 6 of the surgery i.e., a day after the injectable drugs were stopped

Table 1: Prophylactic antibiotic therapy in DFU patients.

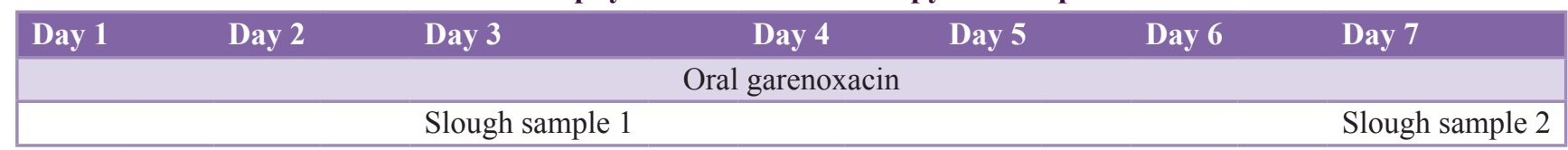

DFU: Diabetic foot ulcer

Table 2: Prophylactic antibiotic therapy in patients with post-surgical intraabdominal wounds.

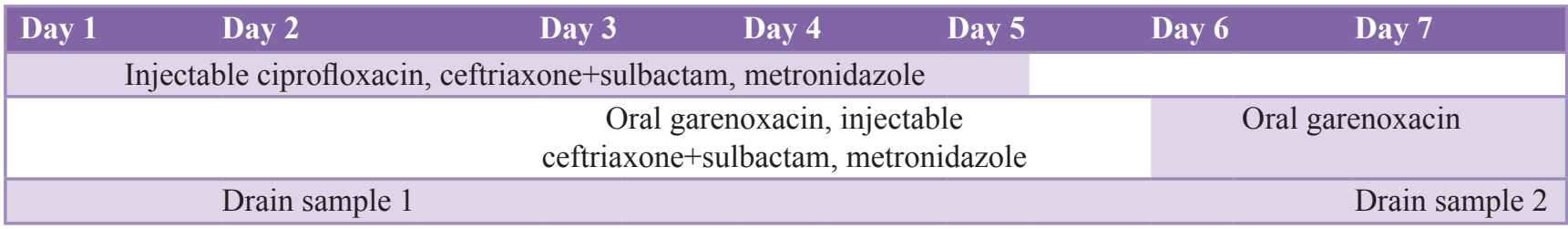


and was sent for evaluation. Total garenoxacin therapy in these patients was 5 days.

\section{RESULTS}

Results from swab culture test DFU patients showed that, initially the most commonly isolated organisms were $S$. aureus, Pseudomonas, Acinetobacter and Klebsiella. Following surgical debridement, 27 samples turned sterile while 2 showed Pseudomonas growth and 1 sample showed growth of Acinetobacter. These patients were advised for indoor admission, for which they were referred to surgical ward.

Slough from the wounds was evaluated in term frequency of change of dressings while desloughing procedure, during the study period and discharge fluid/slough was compared from day 0 on day 5 and 7 . The patients were divided into three categories, viz. treatment failure when reduction in discharge was $\leq 50 \%$, improvement when reduction in discharge was $50-75 \%$ and cure when reduction in discharge was $76-100 \%$ as shown in Table 3.

Results from swab culture test in post-operative infectious intraabdominal wounds showed that, initially the most commonly isolated organisms were Enterococcus and Acinetobacter and Klebsiella. Post garenoxacin administration $2 \times 200 \mathrm{mg}$ for 5 days, $100 \%$ samples were found to be sterile.

Drain discharge was recorded carefully every day during the study period and discharge fluid in the drain was compared from day 0 on day 5 and 7 . The patients were divided into three categories, viz. treatment failure when reduction in discharge was $\leq 50 \%$, improvement when reduction in discharge was 50-75\% and cure when reduction in discharge was $76-100 \%$ as shown in Table 4.

Table 3: Decease in slough/exudate in diabetic foot patients.

\begin{tabular}{|lccc|}
\hline Therapy & \multicolumn{2}{c}{ Wound slough/discharge decrease } \\
\cline { 2 - 4 } & $\begin{array}{c}\mathbf{5} \text { - } \mathbf{5 0} \% \\
\text { (treatment } \\
\text { failure) }\end{array}$ & $\begin{array}{c}\mathbf{5 0 - 7 5 \%} \\
\text { (improvement) }\end{array}$ & $\begin{array}{c}\mathbf{7 5 - 1 0 0 \%} \\
\text { (cure) }\end{array}$ \\
\hline 5 Days & 2 & 21 & 7 \\
\hline 7 Days & 0 & 5 & 25 \\
\hline
\end{tabular}

Table 4: Decease in drain discharge in post-operative intra-abdominal infectious wounds.

\begin{tabular}{|lccc|}
\hline Therapy & \multicolumn{3}{c}{$\%$ Drain discharge decrease in } \\
\cline { 2 - 4 } duration & $\begin{array}{c}\mathbf{5} \mathbf{5 0} \% \\
\text { (treatment } \\
\text { failure) }\end{array}$ & $\begin{array}{c}\mathbf{5 0 - 7 5 \%} \\
\text { (improvement) }\end{array}$ & $\begin{array}{c}\mathbf{7 5 - 1 0 0 \%} \\
\text { (cure) }\end{array}$ \\
\hline 5 Days & 0 & 15 & 55 \\
\hline 7 Days & 0 & 10 & 60 \\
\hline
\end{tabular}

\section{DISCUSSION}

SSSI present as a wide spectrum of disease, and may worsen under unhygienic or if not given proper empirical antibacterial therapy as wound site is more susceptible for acute bacterial infection. This worsening increases the complications especially in diabetic population, patients with low immunity and in case of geriatric age group. Along with the maintenance of proper hygiene at the wound site US FDA recommends the evaluation of microbiology data from the wound site, proper prophylactic empirical antimicrobial therapy and change of dressings along with debridement procedures. ${ }^{8}$ Considering all these recommendations, this study was carefully conducted to evaluate the efficacy and safety of garenoxacin as an empirical antibiotic therapy in SSSIs.

Swab culture from the slough of all the patients enrolled in the study. Among the diabetic foot patients (30) most common organisms isolated from the slough/exudate were S. aureus, Pseudomonas, Acinetobacter and Klebsiella. Mathangi and Prabhakaran (2013) also shown similar bacterial profile in the study which was done in Thanjavur, Tamil Nadu for evaluating bacterial growth from diabetic foot infections. ${ }^{9}$ About $90 \%$ of the isolated cultures turned sterile within 5 days of garenoxacin oral administration. In patients who had postsurgical intraabdominal wound (70), the common isolated organisms were Enterococcus and Acinetobacter and Klebsiella. Shree et al. (2013) also shown similar bacterial profile in the study which was done in New Delhi for evaluating bacterial growth intraabdominal infections, ${ }^{10}$ and similar profile of bacteria was isolated in Japan by Shinagawa et al. (1994), among which the most common was Escherichia coli, followed by Bacteroides fragilis, anaerobic cocci, Enterococcus spp. and Klebsiella spp., ${ }^{11}$ though a $B$. fragilis, anaerobic cocci and Enterococcus spp. were not isolated which may be due to change in geographical location.

Second most important parameter which was evaluated was the quantum of slough or exudates from DFUs and drain discharge in infectious intraabdominal post-surgical wound. In DFU patients on day 5, 6\% (2) patients showed treatment failure, $70 \%$ (21) patients showed improvement in wound infection and 24\% (7) patients showed cure as the slough was reduces by almost $100 \%$ in these cases. At the end of $7^{\text {th }}$ day, there was no patient in treatment failure group, 16\% (5) patients showed improvement and $84 \%$ (25) patients wound showed cure. Initial treatment failure was probably due to inadequate control on blood sugar levels, and improper wound hygiene. However with the use of garenoxacin, after 7 days of therapy there was no treatment failure and $84 \%$ of wound showed cure. In case of infectious intraabdominal post-surgical wound, there was no treatment failure case reported on day 5, however $21 \%$ (15) patients showed improvement in wound healing and $79 \%$ (55) patients showed cure. After 7 days of therapy cure was observed in $86 \%(60)$ patients. 
There was no side-effect reported from the patients who were prescribed garenoxacin empirical therapy for their wound healing.

\section{CONCLUSIONS}

Administration of garenoxacin used as empirical therapy for surgical prophylaxis and as switch therapy in patients with DFUs and post-surgical infectious wounds for the period of 5-7 days has been found effective against gram positive, gram negative and atypical organisms indicating its wide spectrum of action.

\section{ACKNOWLEDGMENTS}

We acknowledge the contribution of Dr. Amit Bhargava, VP and Head Medical Services - Glenmark Pharmaceuticals Mumbai and Dr. Anoop Hajare - Medical Advisor - Glenmark Pharmaceuticals Mumbai.

\section{Funding: No funding sources}

Conflict of interest: None declared

Ethical approval: Retrospective case study series conducted and analyzed with no ethical considerations

\section{REFERENCES}

1. Bisno AL, Stevens DL. Streptococcal infections of skin and soft tissues. N Engl J Med. 1996;334(4):240-5.

2. Janda JM, Abbott SL, Brenden RA. Overview of the etiology of wound infections with particular emphasis on community-acquired illnesses. Eur J Clin Microbiol Infect Dis. 1997;16(3):189-201.

3. Lipsky BA. Evidence-based antibiotic therapy of diabetic foot infections. FEMS Immunol Med Microbiol.
1999;26(3-4):267-76.

4. Woods RK, Dellinger EP. Current guidelines for antibiotic prophylaxis of surgical wounds. Am Fam Physician. 1998;57(11):2731-40.

5. Giordano P, Weber K, Gesin G, Kubert J. Skin and skin structure infections: treatment with newer generation fluoroquinolones. Ther Clin Risk Manag. 2007;3(2):309-17.

6. Ince D, Zhang X, Silver LC, Hooper DC. Dual targeting of DNA gyrase and topoisomerase IV: target interactions of garenoxacin (BMS-284756, T-3811ME), a new desfluoroquinolone. Antimicrob Agents Chemother. 2002;46(11):3370-80.

7. Vora A. Garenoxacin. J Assoc Physicians India. 2014;62(1):34-5.

8. Guidance for Industry Acute Bacterial Skin and Skin Structure Infections: Developing Drugs for Treatment. U.S. Department of Health and Human Services Food and Drug Administration Center for Drug Evaluation and Research (CDER); 2013.

9. Mathangi T, Prabhakaran P. Prevalence of bacteria isolated from type 2 diabetic foot ulcers and the antibiotic susceptibility pattern. Int J Curr Microbiol Appl Sci. 2013;2(10):329-37.

10. Shree N, Arora BS, Mohil RS, Kasana D, Biswal I. Bacterial profile and patterns of antimicrobial drug resistance in intra-abdominal infections: current experience in a teaching hospital. Indian J Pathol Microbiol. 2013;56(4):388-92.

11. Shinagawa N, Mizuno A, Mashita K, Yura J, Ishikawa S, Hirata $\mathrm{K}$, et al. Bacteria isolated from intraabdominal infection and their susceptibilities to antimicrobial agents. Jpn J Antibiot. 1994;47(10):1329-43.

doi: $10.5455 / 2319-2003 . i j b c p 20150226$

Cite this article as: Rodrigues $\mathrm{J}$, Ramani $\mathrm{A}$, Mondarkar S, Nazareth M, Sobti V, Krishnaprasad K. Use of garenoxacin: a new generation antibiotic for surgical infections. Int $\mathrm{J}$ Basic Clin Pharmacol 2015;4:144-7. 